\title{
On the Popularization of Marxist Philosophy in Contemporary
}

\author{
China \\ Xiao Ling ${ }^{1 *}$ \\ ${ }^{1}$ Jiangsu University, Zhenjiang, Jiangsu \\ *Xiao Ling, E-mail: 1306160554@qq.com \\ Received: July 18, 2017 \\ Accepted: July 29, 2017 \\ Online Published: August 11, 2017 \\ doi:10.22158/wjssr.v4n3p231 \\ URL: http://dx.doi.org/10.22158/wjssr.v4n3p231

\begin{abstract}
The popularization of Marxist philosophy has always been the key research content of researchers. It is also the basic condition for the deep analysis of the objective law. During the modern development and construction in China, it needs to use empirical researches and dynamic theories to promote the analysis of the popularization of Marxist philosophy in China. The paper analyzes the problems existing in the popularization of Marxist philosophy in contemporary China and then studies the development path.
\end{abstract}

\section{Keywords}

contemporary China, Marxist philosophy, popularization

\section{Introduction}

At present, China is in its critical period of the social transformation. The rapid development of science and technology as well as the construction of economic globalization will produce a series of contradictions and disputes. First, the mainstream ideas become more active and the collisions between different cultures get more intense; second, the access to the public information is gradually increased and the information selection becomes more targeted. It also indicates that the contemporary popular psychology and spirit have entered a new development stage, making the implementation of the Marxist philosophy more difficult.

\section{Connotation of the Popularization of Marxist Philosophy}

\subsection{Critical Connotation}

In fact, philosophy is to criticize society and establish the critical philosophical truth. In other words, criticism is the most basic property of Marxist philosophy. Based on these critical contents, Marx established his own philosophical system, which criticized his own philosophical theory as well as the real life. 
Marx clearly states that dialectics makes a real analysis of things, understands all the properties of things and obtains the forms in the continuous development so as to determine the transience and timeliness. From the essential level, Marxist philosophy criticism does not just adore a certain kind of things, but also promotes its own development continuously with the help of critical means. It can be seen that Marxist philosophy is an open system, which can be improved with the development of the times.

\subsection{Practical Connotation}

Marxism regards people as special individuals. Marxist philosophy argues that people are actually independent and realistic individuals with consciousness. Marxist philosophy has repeatedly stressed people's independently innovated values.

The traditional materialism views the world from the emotional perspective and considers the world as a natural thing. The practical materialism analyzes the naturalization of people and the historical development process. Marxist philosophy believes that the practical connotation has the characteristics of the proletariat. As a weapon of Marxist philosophy, the proletariat is also the spiritual value of Marxist philosophy. Marxist philosophy is not the philosophy of the minority but the philosophy of the public.

\section{Problems of the Popularization of Marxist Philosophy in Contemporary China}

\subsection{Marginalization and Self-Exile}

\subsubsection{Marxist Philosophy with Weakened Philosophical Tension}

Tension is actually the attraction between different molecules in the field of physics. The philosophical tension defines a new meaning based on it. The philosophical tension connects different contradictions. At the same time, with the identity and differences, it obtains the balance point between dynamic and static state.

Actually, the spirit of philosophical theory is the combination of reality and the theoretical spirit. Therefore, the popularization of the philosophical theory is also an inevitable development trend. When applied in the political field, philosophy can involve the theory in practice. As a theoretical feature, philosophy is similar to the real world, and it is also a reflection of the real world. For anyone who wants to achieve his own value or devour the politics, philosophy needs to break through itself and keeps consistent with the development process of the times. The relationship between the world philosophization and the philosophy cosmopolitanization shows the relationship between reality and abstraction. In the process of responding to the real world, the self-tension of Marxist philosophy decreases and its philosophical nature is weakened, with its value greatly reduced. 


\subsubsection{Marxist Philosophy with Pan-Ideologization}

From the political level, as a main political means in China, Marxist philosophy has gradually become a tool to control the thinking of the contemporary mass. Under the negative information and utilitarian ideas, the philosophical value of Marxist philosophy declines significantly. Currently, there are many research results of the Marxist philosophy as a whole. However, those with innovation are very limited. Marxist philosophy has thus been reduced to an anthem in the government policies.

\section{Virtual Technology and Marxist Philosophy}

The rapid socio-economic development has brought more knowledge of fast-food style, thus generating a gradually weakening philosophical function. People don't gain insight into the connotation of the philosophy. In particular, amid the rapid development of network and information technologies, Marxist philosophy comes under impact from various aspects.

1) Impact on the Traditional Philosophical Material View

The essential parts of Marxist philosophy are the concepts of materials and practice. With the development of the Internet virtual technology, a new topic of the virtual and the real world has been put forward. The boundaries between the real world and the network environment are becoming more blurred. People can use data as tools and virtual means to transmit the information. Meanwhile, they can use virtual means to create more information denied by the real world.

People can transform the world and they are also subject to the objective materials. Through the comparison between the real and the virtual worlds, people can deploy information technologies to simulate the delay, such as VR technology. In reality, communications between people are mainly achieved through meetings or letters. The Internet technology breaks through constraints of the time and space. It is more convenient for people to communicate via the network. By means of the virtual technology, people can virtualize the scenes they want. As the traditional Marxist philosophy does not contain the virtual connotation, it has a certain impact on the traditional Marxist philosophy.

2) Impact on the Dominant Position of Marxist Philosophy

In the development of economic globalization, China has gradually entered upon the Internet era when the information technology develops rapidly, the amount of information increases significantly and people are living an enriched life, which has also transformed into people's daily life style.

First, during its development, the computer technology has promoted the social reform and changed people's lives as well as consumption habits against the backdrop of the re-creation of economic base and superstructure. In the social context of a new era, the masses are gradually influenced by the new concepts, thus raising doubts of some people in the traditional mainstream ideas.

Second, cultural output from some countries to China is active by dint of the Internet technology, and the Western cultural concepts become acceptable. There are some differences between the Western moral values and the traditional Chinese ideas of lifestyles. Some netizens are attracted by the Western 
moral concepts, resulting in the confusions of their own ideas, thus leading to problems in their outlooks of life as well as world views, which further exacerbates the complexity of the political values.

\section{Popularization Path of Marxist Philosophy in Contemporary China}

\subsection{Essential Regression of Marxist Philosophy}

\subsubsection{Criticism of Marxist Philosophy}

The ultimate goal of Marxist philosophy is to realize the comprehensive and independent development of people and liberate the proletariat. Marxist philosophy critically lays the foundation of the modern philosophical forms and patterns, giving the times the virtual criticism. In the face of the actual reality, philosophy can find not only the good side of society, but also the contradictions existing in it. It identifies the problems that constraint the social development and construction, criticizes them and then creates new social concepts.

The critical nature of the philosophy belongs to an open system and it will change with the development of the times. The contradictions existing in the social development can be essentially solved with the rebellion of the capital logic as the basic condition. The critical regression of philosophy is the prerequisite for the construction of Marxist philosophy in China. In other words, after the popularization construction of the philosophical criticism, the philosophical thinking can be simplified and the self-consciousness awakened to stimulate the potential contradictions and disputes in the society. Philosophy is not a master key. It actually exists in anything, and is generated by criticizing things.

\subsubsection{Problem Consciousness of Marxist Philosophy}

The problem awareness lies not just in finding and examining problems, but more to solve problems and deal with problems. Marx believes that problems needed to be solved urgently by the times have their root reasons regarding content. They also embody a certain historical mission. It is difficult to obtain the problems instead of the answers. It is the problem rather than answer that is to be really criticized. With the critical analysis as the basic condition, the problem consciousness has become the starting point of Marxist philosophy to solve social contradictions and dispute. It has also become the key research content of the humanistic society.

Marxist philosophy forms and the social class disputes emerge in the most intense period. Then Marx analyzes the comprehensive development of human beings as philosophy started from the liberation of people's development. The Marxist philosophy is the most prominent manifestation of the description of the historical development law. Instead of the historical materialism, it analyzes through the contradictions within the capitalist society. It also shows that, although Marxist philosophy has also analyzed the philosophical problems, more problems are considered by taking the philosophical issues as the starting point. 
When the society develops to a certain stage, it will show different characteristics, while in general, the society will finally become a unity. A part of society cannot be further developed, while only the overall history can make it. Comprehensiveness and complexity emerge concerning the problems in the development of contemporary China. Therefore, the problem consciousness needs to be integrated with the integrity.

The study of Marxist philosophy considers the integrated research as a basic condition. Marxist philosophy has self-consciousness, believing that people play an important role, which cannot be ignored in the pursuit of ideals and the development of reality. Marxist philosophy is an objective statement, which guides people's thinking in an active manner.

\subsection{The Internet Age and the Popularization of Marxist Philosophy}

\subsubsection{Carrier Innovation of Marxist Philosophy}

There are new and popular network communication forms, providing a good platform for the development of Marxist philosophy. In the large amount of information, most netizens are actually highly loyal to the Communist Party of China, willing to comment on the national development. With the network platform functioning as medium, people can actively express their own ideas and meanwhile guarantee the availability and timeliness of information.

The development and popularization of Marxist philosophy needs the help of the mass media. With the development of the Internet, the people's civic awareness has been improved significantly. Marxist philosophy should take advantage of the social atmosphere to actively ease people's ideas and philosophies. First, the network media can feedback the information in an active manner. Second, the network platform can achieve good results in information publication.

\subsubsection{Thinking Broadening of Marxist Philosophy}

Virtuality is the most significant feature of the Internet, which means that when netizens express their own ideas, their identities can be virtualized and there's no need for them to bear the responsibility of speech. With the essence of the popularization of Marxist philosophy weakening in the real world, it should turn to strengthen its role in the virtual environment. Besides, it should build an equal and free network platform based on the Internet environment characteristics, focus on the latest academic research results and positively feedback the views of netizens, carrying out the construction of the popularization of Marxist philosophy in various ways.

\subsubsection{Subject Integration Promotion}

As the core content of the Marxist ideology, Marxist philosophy is the main means for the proletariat and the public to understand the world, and it is also the greatest contribution of philosophy to date.

Throughout the entire network system, Marxist philosophy can hardly be expressed intensively and professionally only by using one search engine. There is basically academic literature on the relevant search engines and the sites are designed in a simple way, causing failure in being attractive. In the sub-consciousness of most people, Marxist philosophy belongs to the professional research content, not 
applicable in people's actual life. These misconceptions are very unfavorable to the popularization of Marxist philosophy, but it also helps produce a large number of Marxist philosophy professionals in converging into a new spreading force. Marxist philosophy needs a long development process for truly realizing the popularization. Professionals should play a leading role in creating a new network platform and embracing different views.

\section{Conclusion}

The analysis of the popularization issues of the Marxist philosophy in contemporary China and the understanding of its development path are of great significance in enriching its theoretical system. Through the preliminary analysis, the paper holds that for the popularization and development of Marxist philosophy, different social problems should first be sorted out to grasp the essence of Marxist philosophy and know the opportunities as well as challenges brought by the development of the Internet. Only by this way can the popularization of the Marxist philosophy in contemporary China be essentially realized.

\section{References}

Cui, L. (2015). Exploration of the Real Path of the Popularization of Marxist Philosophy in Contemporary China. Dongyue Tribune, 2015(06), 41-46.

Teng, J. B. (2014). On the Basic Principles and Advancing Path of the Popularization of Marxist Philosophy in Contemporary China. Science \& Technology Vision, 2014(36), 184-314.

$\mathrm{Wu}, \mathrm{Z}$. Y. (2016). Engels and the Popularization of Marxist Philosophy in China-Taking Ludwig Feuerbach and the End of Classical German Philosophy as an Example. Journal of Ideological \& Theoretical Education, 2016(01), 24-27.

Zhong, Z. Q., \& Yang, Q. H. (2010). Philosophical Implications of the Popularization of Marxist Philosophy in Contemporary China. Journal of Ideological \& Theoretical Education, 2010(06), 35-37. 